\title{
Mechanical Properties Analysis of Al2024 alloy Submitted to Different Aging Time and different Cold Plastic Deformation degree
}

\author{
Marcelo Luis Siqueira $^{a *}$, Aline da Silva ${ }^{a}$, Mirian de Lourdes Noronha Motta Melo ${ }^{a}$, Geovani Rodrigues $^{a}$ \\ ${ }^{a}$ Departamento de Engenharia Mecânica, Universidade Federal de Itajubá - UNIFEI, Campus Prof. \\ José Rodrigues Seabra, 37.500-903, Itajubá, MG, Brasil
}

Received: September 02, 2018; Revised: April 12, 2019; Accepted: May 02, 2019

\begin{abstract}
Brazilian aeronautical industries report that, due to the high mechanical properties presented commercially, AA2024-T351 alloy presents fissures and non-homogeneous deformations during the mechanical processing. This work proposes a manufacturing process capable of increasing the ductility of the material to withstand tensions during processing and a subsequent treatment to recover the mechanical strength of the alloy. The sequence of operations begins with the super-heat treatment at $415^{\circ} \mathrm{C} 2.5 \mathrm{~h}$, solubilization at $495^{\circ} \mathrm{C} 2.0 \mathrm{~h}$, mechanical conformation with a degree of area reduction from $10 \%$ to $90 \%$ and artificial aging at $190^{\circ} \mathrm{C}$ at times of 2, 4, 6 and 8 hours. The results allowed to obtain an operational sequence where it is possible to form the alloy in the desired component, without loss of mechanical properties and structural defects, in the shortest time possible of heat treatment, reducing the manufacturing costs and increasing productivity.
\end{abstract}

Keywords: AA2024 alloy, overaging, solubilization, cold Rolling, artificial aging and mechanical properties.

\section{Introduction}

Brazil ranks as the $2^{\text {nd }}$ largest bauxite producer in the world ( $14 \%$ of production), however occupies only $6^{\text {th }}$ place when it comes to aluminum production, behind all other countries that make up the so-called BRICs: Brazil, Russia, India and China ${ }^{1}$. The position in the production ranking reflects the Brazilian deficiency in the technologically more noble stages and, consequently, adds more value, such as bauxite refining, alumina reduction and, mainly, aluminum processing ${ }^{1}$. More than a century after the discovery of the phenomenon of precipitation hardening and the expressive use of the AA2024 alloy in the aerospace industry ${ }^{2-3}$, Brazil still outlines timid steps in relation to the technological domain of this manufacturing technique. The basic requirements for aircraft production are low weight, high mechanical strength, corrosion and fatigue resistance, in-service hardenability, good machinability, weldability and reasonably low $\operatorname{cost}^{4-6}$. In addition to the requirements imposed by the increasingly competitive market, the reduction of fuel consumption, shorter time between repairs and longer component life are vital factors for business survival ${ }^{7}$.

Currently in Brazil, precipitation hardenable aluminum alloys, such as AA2024 used in the aerospace industry, are imported in their commercial form, that is, solubilized and aged - condition T351. In this case, the required properties are $470 \mathrm{MPa}$ for the rupture stress and $137 \mathrm{HV}^{8}$.
However, if there is a need for the alloy to be formed, national industries have warned that mechanical properties often become unstable, even with cracking during processing, possibly due to excessive hardness increase. The reasons for these differences in strength, hardness and requirements for the subsequent processes are still uncertain, but the working conditions must be better established in order to obtain better properties without compromising the structural integrity of the component. In this case, the softening of the alloy due to over-aging, it is a fundamental technique so that future stages of conformation are carried out without the formation of cracks. In addition, it is expected that the internal energy stored by the forming process favors the rate of precipitation reaction during the artificial aging treatment. Consequently, one can expect a productivity gain due to reduction in treatment time and saving of electricity.

\section{Experimental Methods and Procedures}

It was used the aluminum alloy AA2024 T351 with a thickness of $4.5 \mathrm{~mm}$ whose chemical composition is given in Table 1.

Table 1. Chemical composition of aluminum alloy AA2024 T351 (wt \%).

\begin{tabular}{ccccccc}
\hline $\mathrm{Cu}$ & $\mathrm{Mg}$ & $\mathrm{Mn}$ & $\mathrm{Si}$ & $\mathrm{Fe}$ & $\mathrm{Zn}$ & $\mathrm{Ti}$ \\
\hline 4,10 & 1,30 & 0,46 & 0,08 & 0,16 & 0,22 & 0,03 \\
\hline
\end{tabular}


To confirm related problem by aircraft Brazilian industries, was used a commercial alloy AA2024 T351, dimensions $352 \times 83 \times 23 \mathrm{~mm}$, Figure 1 .

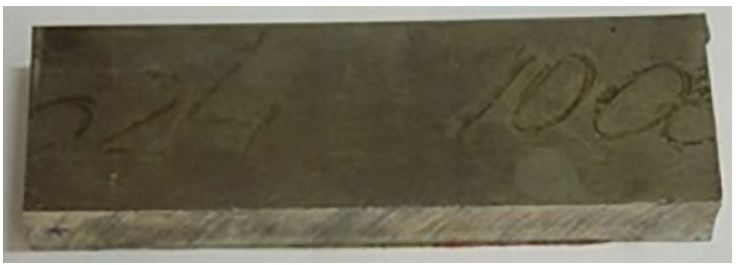

Figure 1. Commercial AA2024 aluminium alloy.

A rolling machine, model LE-300, roll diameter $350 \mathrm{~mm}$, rotation speed $15 \mathrm{rpm}$ was used to reducing plate thickness simulating manufacturing step. After 7 cold rolling steps, inhomogeneous deformation was present and not considerable thickness reduction was observed, Figure 2. In steps sequence, the material was degraded and after 10 cycles, the material collapse, Figure 3 .

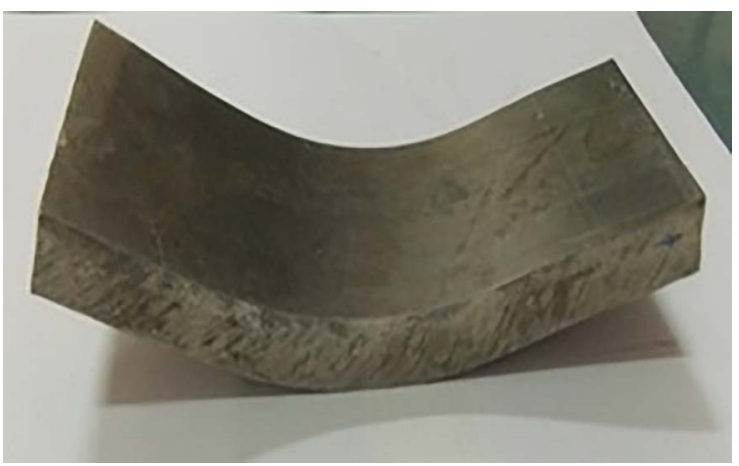

Figure 2. Commercial AA2024 aluminium alloy after 7 steps of cold rolling.

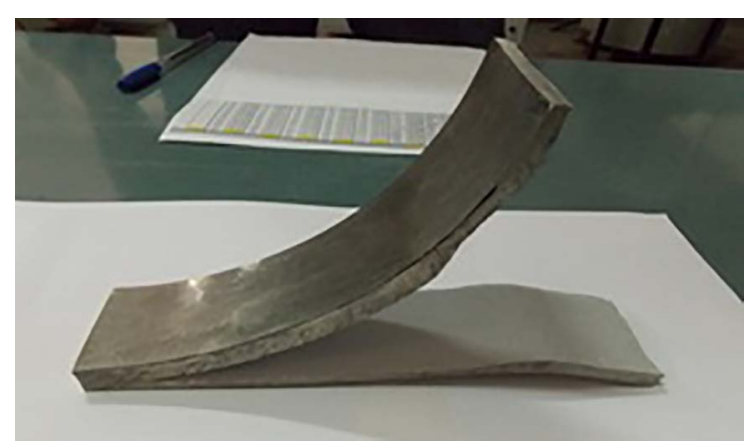

Figure 3. Commercial AA2024 aluminium alloy after 10 steps of cold rolling.

Once confirmed the problem related by aircraft manufacturers, next step is to reduce the mechanical properties of the as-received alloy.

A plate of AA2024 aluminium alloy was subjected to an overaging heat treatment at about $415^{\circ} \mathrm{C}$ for 2.5 hours. Next, the plate was solubilized at $495^{\circ} \mathrm{C}$ for 2 hours.
Then, the samples were cold rolled range from $10 \%$ to $90 \%$ in area, using a reduction rolling machine with a rotational speed of $15 \mathrm{rpm}$. It is notable that a group of sample was not subjected to plastic deformation. The main purpose of performing various cold rolled reducing of samples was to obtain different microstructures to show their effects on the mechanical properties. Different times were used to artificial aging heat treatment $(2,4,6$ and 8 hours) (Figure 4 and Figure 5).

The microstructure changing was determined by optical microscopy, scanning electron microscope (SEM), Vickers Microhardness, tensile test and electrical conductivity. For the microstructural analysis, the specimens were ground with 120, 320, 400, 600, and 1200-grit SiC papers and polished with 3 diamond suspension, $1 \mu \mathrm{m}$ diamond paste and colloidal silica. Then, samples were etched with a Keller solution to determine the microstructure using optical microscope Leica, model DMI 5000M image analyzer LAS V-4.5) and scanning electron microscope (Jeol, model JXA-840A). The Vickers microhardness was also measured on all samples in the central regions based on standard ASTM 384-179. Each hardness result was determined from an average of fifteen measurements per sample with a $4.9 \mathrm{KN}$ indentation load $500 \mathrm{gf}$ in the rolling direction. In addition, tensile tests were performed based on the standard ASTM E8M- $00 b^{10}$ on samples with a gauge length of $25 \mathrm{~mm}$ and overall length of $100 \mathrm{~mm}$ under a strain rate of $5 \mathrm{~mm} /$ minute at room temperature.

\section{Results and Discussions}

According Radutoiu et al. ${ }^{11}$ the aging treatment promotes the hardening of the alloy 2024 and the degree of aging is a function of time and temperature used for treatment. In this study, temperature was kept constant $\left(190^{\circ} \mathrm{C}\right)$ and therefore, the variation of the time and cold rolling were responsible for the change in mechanical properties.

The cold plastic deformation of the alloy from the metastable condition of metallurgical microstructure increases the dislocation density, which favors the atomic diffusion of solute atoms. It also elevates the response to treatment of aging, resulting in an intense effect in increasing alloy strength ${ }^{12-14}$. Aging reactions begin to occur at lower temperatures and response to age hardening is a hardening of the sum of the contribution and the presence of precipitates ${ }^{5}$.

The cold deformed AA2024 alloy has two mechanisms, which are responsible for the increased resistance. The first is related to stage 1 , where the hardening is derived from the combined effect of work hardening caused by the introduction of dislocations during cold rolling and Guinier Preston precipitates formed during the aging treatment. The second mechanism refers to the decrease of the effect caused by hardening, through the annihilation of dislocations and increased effect caused by the growth and aging phase $\mathrm{S}^{\prime} \mathrm{Al}_{2} \mathrm{CuMg}$ composition ${ }^{12}$. 


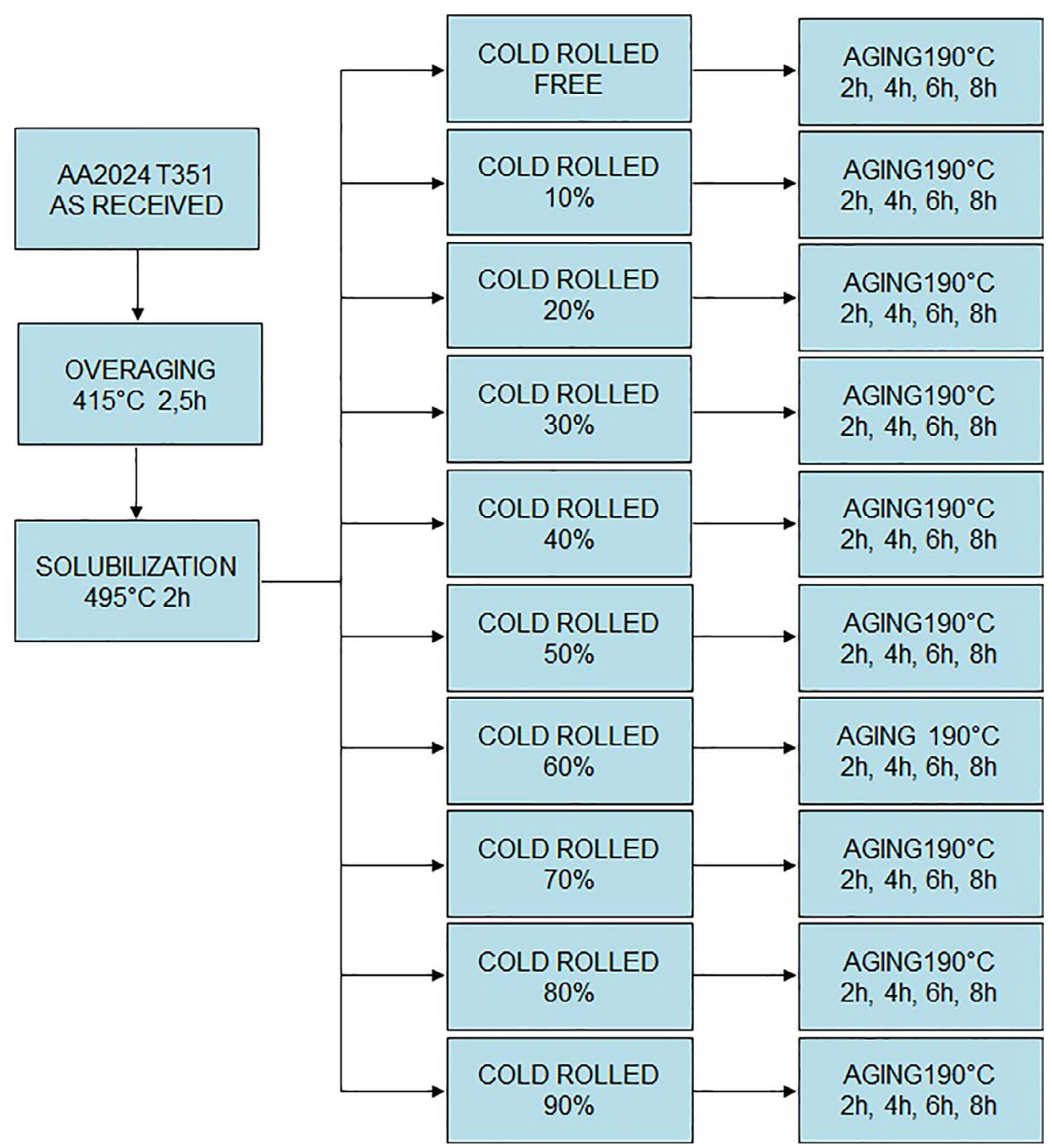

Figure 4. Route used for aluminium alloyAA2024 analysis.

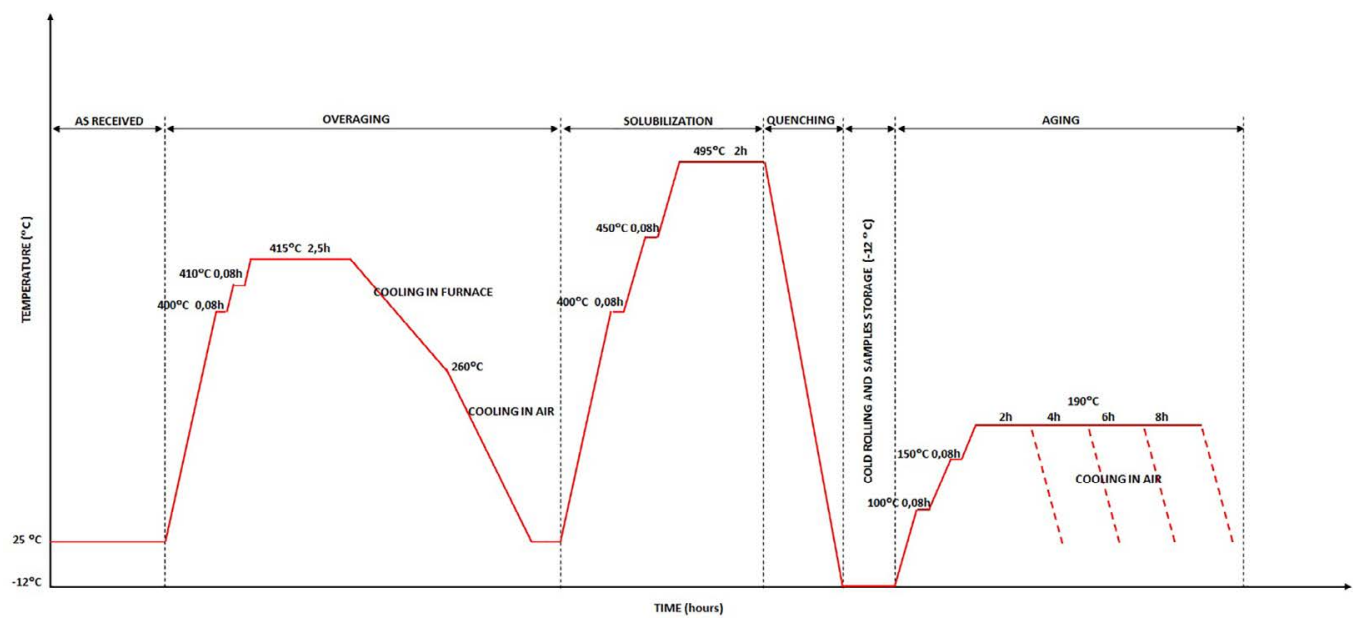

Figure 5. Heat treatment route for aluminium alloy AA2024. 
Bagaryatsky ${ }^{15}$ proposed the following aging sequence:

$$
\mathrm{SSS} \longrightarrow \mathrm{GPB} \text { zones } \longrightarrow \mathrm{S}^{\prime \prime} / \mathrm{GPB} 2 \longrightarrow \mathrm{S}^{\prime} \longrightarrow \mathrm{S}
$$

SSS refers to supersaturated solid solution, GPB refers to Guinier-Preston-Bagaryatsky zones and S" and S' are the precursors of the equilibrium phase $\mathrm{S}\left(\mathrm{Al}_{2} \mathrm{CuMg}\right)$. According to Elgallad et al. ${ }^{16}$ there is an emerging view that the differences between GPB, GPB2 and S" are insufficient to be firmly confirmed, and these three constituents are generally referred to as GPB zones.

The effect of aging and the effect of cold rolling can be observed in Figure 6.
The maximum value of microhardness achieved during ageing increases when increasing the deformation. Hardening due artificial aging takes more time to occur compared with cold rolled samples aged. Similar results were found by Naimi et al. ${ }^{17}$.

In the last case, aging and plastic deformation act to accelerate the hardening and the maximum linear deformation values indicates more mechanical resistance independent of the aging time used, Figure 7.

In accordance Sjölander and Seifeddine ${ }^{18}$, the ability of the alloy to increase strength during the aging treatment can be defined as the difference between the hardness of solubilized samples and aged samples.

\section{MICROHARDNESS BEHAVIOUR BETWEEN CRF VERSUS $90 \%$ COLD ROLLED SAMPLES IN DIFFERENTS AGING TIME}

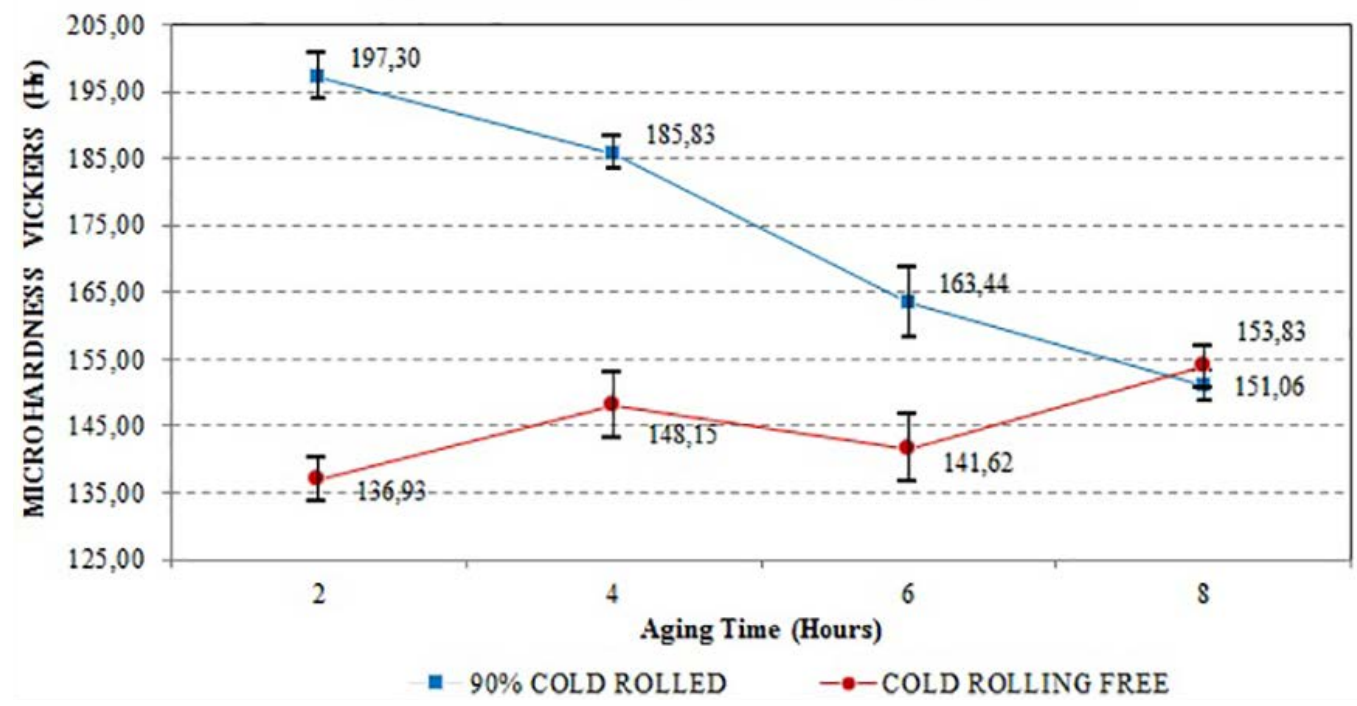

Figure 6. Microhardness Vickers for aluminium alloy AA2024 Cold Rolling Free (CRF) and Cold Rolled

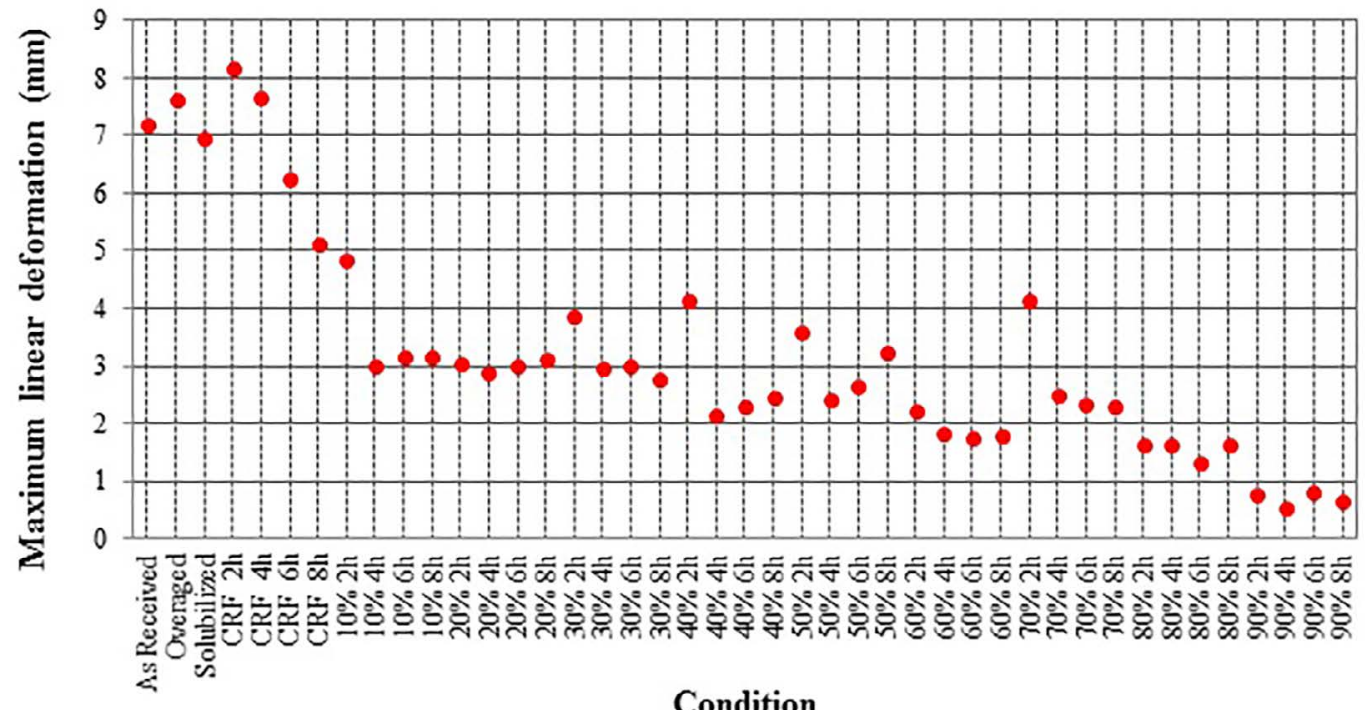

Figure 7. Maximum strain for aluminium alloy AA2024 in different conditions. 
Thus, a comparison was performed to confirm the contribution of microhardness increasing by aging heat treatment effect and cold rolled effect (Figure 8).

In relation metallography analysis, in the alloy AA2024 as received, elonged grain due the cold rolling are present, Figure 9.

For sample extremely cold rolled, $90 \%$, independent of aging time used $(2,4,6$ or 8 hours), it can be observed recrystallization phenome did not is present. Certainly, aging temperature used in this work was not enough to reach the initial temperature of recrystallization (Figure 10).

Intermetallic compounds can be observed in Figure 11 to Figure 13.

Analyzing the distribution profile of the elements in Figure 11 to Figure 13 note the presence of elements Al, $\mathrm{Cu}, \mathrm{Mn}, \mathrm{Fe}$ and $\mathrm{Si}$ in the points indicates. According to Liu et al. ${ }^{19}$, Schneider et al. ${ }^{20}$ and Hughes et al. ${ }^{21}$, they are intermetallic compounds of type Al-Cu-Mn-Fe-Si.
These intermetallic compounds were probably formed during the solidification. According to Moy et al. ${ }^{6}$ the artificial aging has no effect on them.

The insolubility these intermetallic compounds occurs mainly because of the presence of Fe and/or Si impurities, which in commercial alloys for structural applications are often present due to the high cost of reducing impurities ${ }^{22}$.

Precipitation phenomenon act directly on electrical conductivity of AA2024 alloy. During aging, by heating the super satured aluminium alloy, the excess solute elements produce fine particles (according to the precipitation sequence previously cited). This process affects the conductivity by two competitive mechanisms. The first mechanism is the purification of matrix from the removed alloying elements and decreasing of the vacancies retained in the alloy after quenching from solution treating process. These two phenomena increase the electrical conductivity. The second mechanism is the scattering of the conduction electrons due precipitations fine particles which reduces the electrical conductivity ${ }^{23}$.

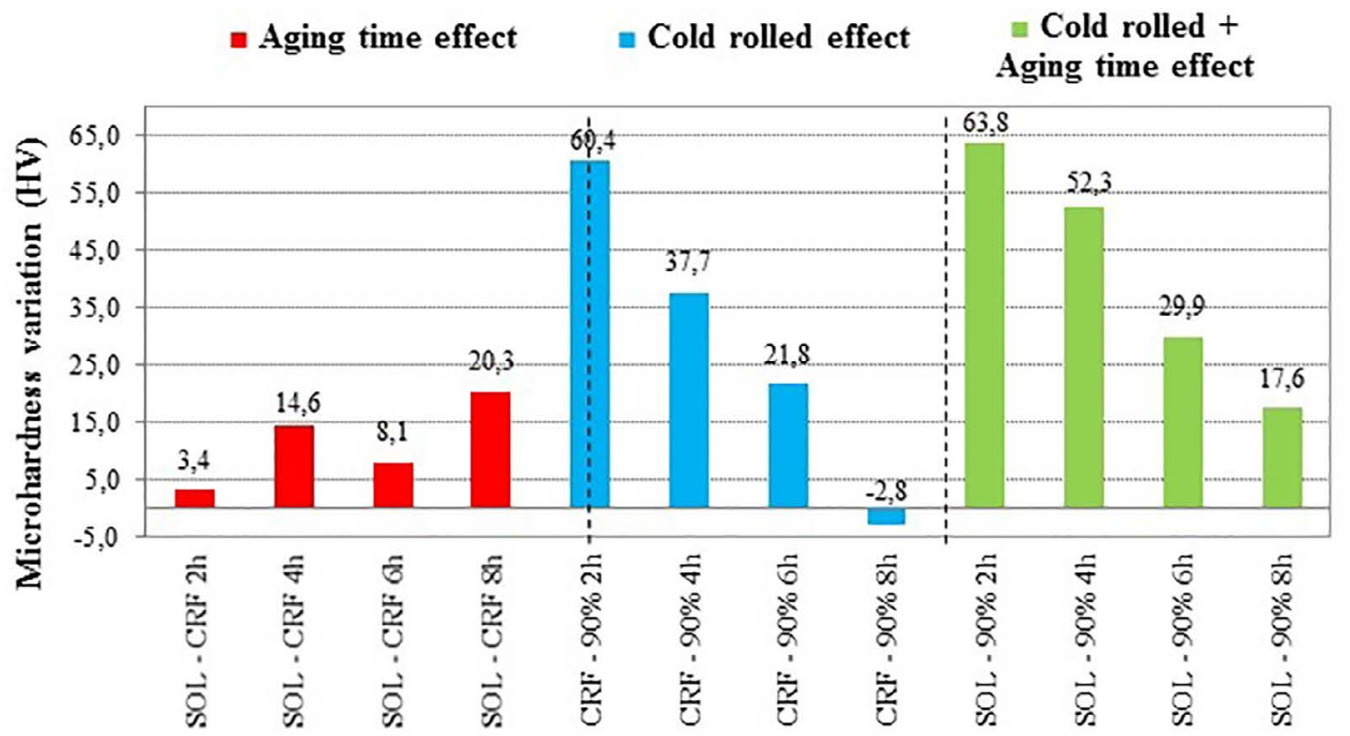

Figure 8. Effects of aging time and cold rolling in the microhardness in the aluminium alloy AA2024.

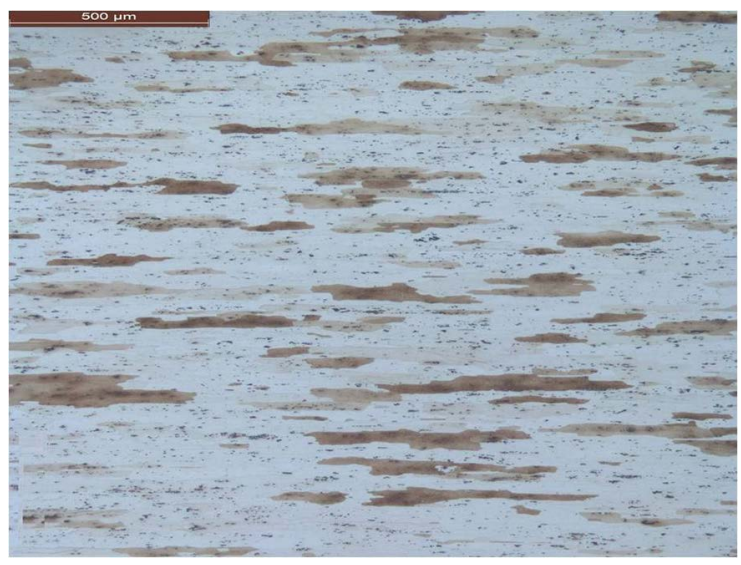

Figure 9. Aluminium alloy AA2024 as received.

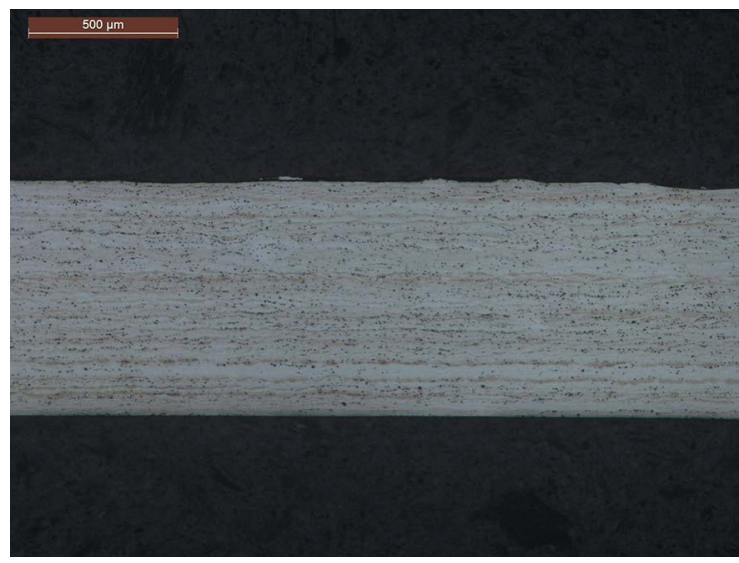

Figure 10. Aluminium alloy AA2024 cold rolled 90\% 2h. 

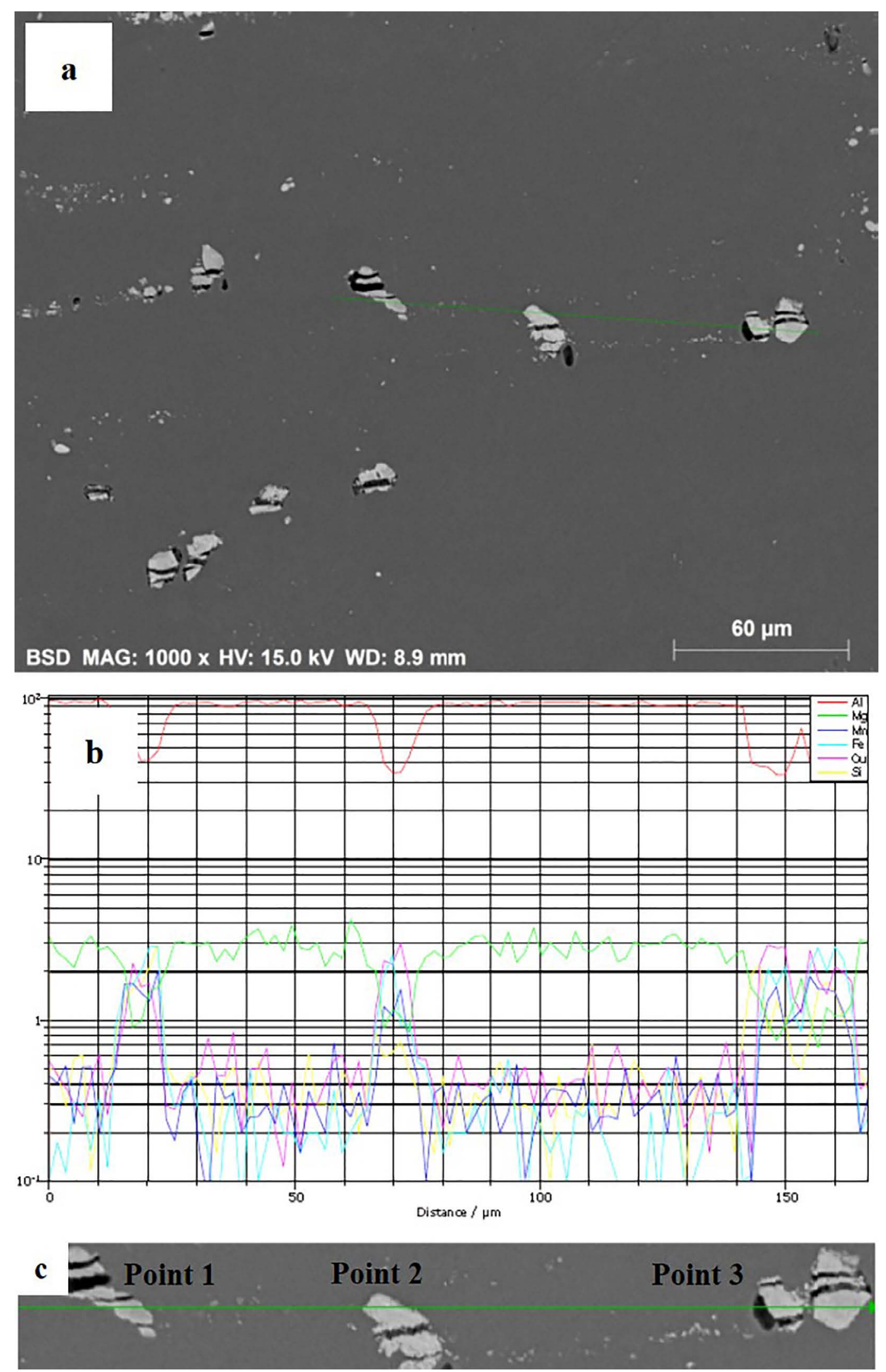

Figure 11. (a) Microstructure of AA2024 alloy deformation free and aged for 2 hours (CRF 2h) with spotlight for the region swept away no line scan. (b) Distribution profile of the main elements of the AA2024 alloy free of deformation and aged for 2 hours (CRF 2h). (c) Magnification of the sweep line. 

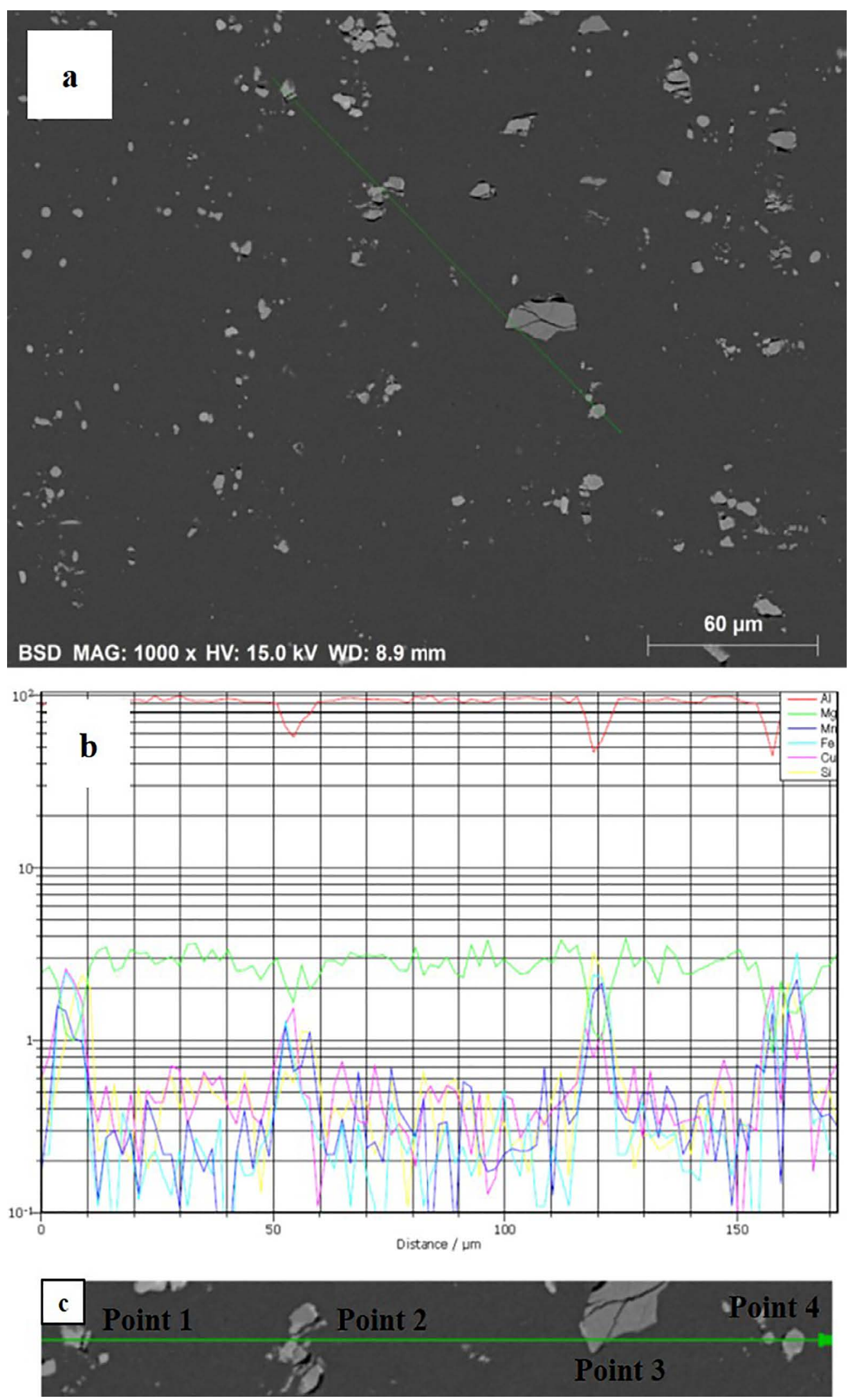

Figure 12. (a) Microstructure of AA2024 alloy cold rolled $90 \%$ and aged for 2 hours with spotlight for the region swept away no line scan. (b) Distribution profile of the main elements of the AA2024 alloy cold rolled $90 \%$ and aged for 2 hours. (c) Magnification of the sweep line. 

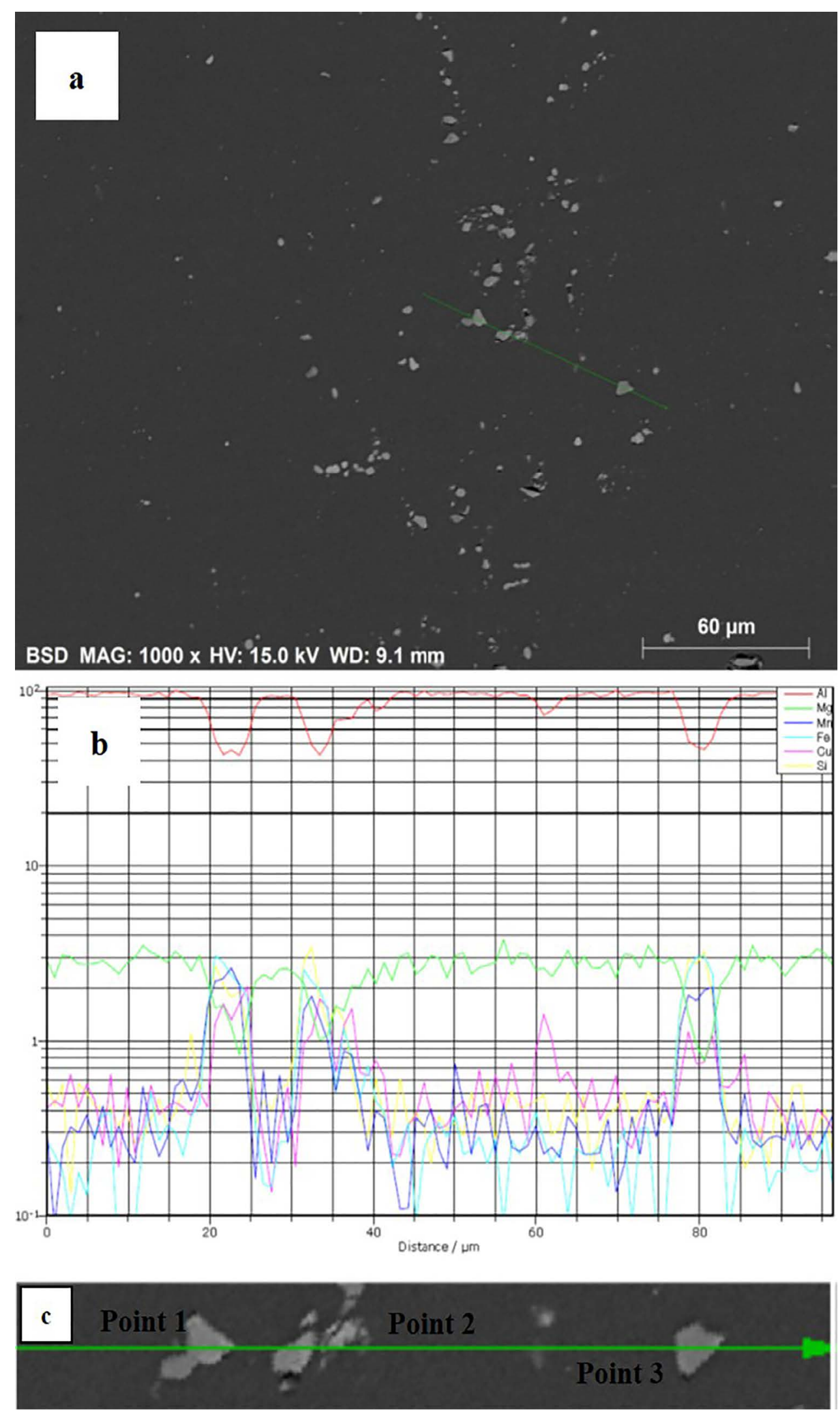

Figure 13. (a) Microstructure of AA2024 alloy cold rolled $90 \%$ and aged for 8 hours with spotlight for the region swept away no line scan. (b) Distribution profile of the main elements of the AA2024 alloy cold rolled $90 \%$ and aged for 8 hours. (c) Magnification of the sweep line. 


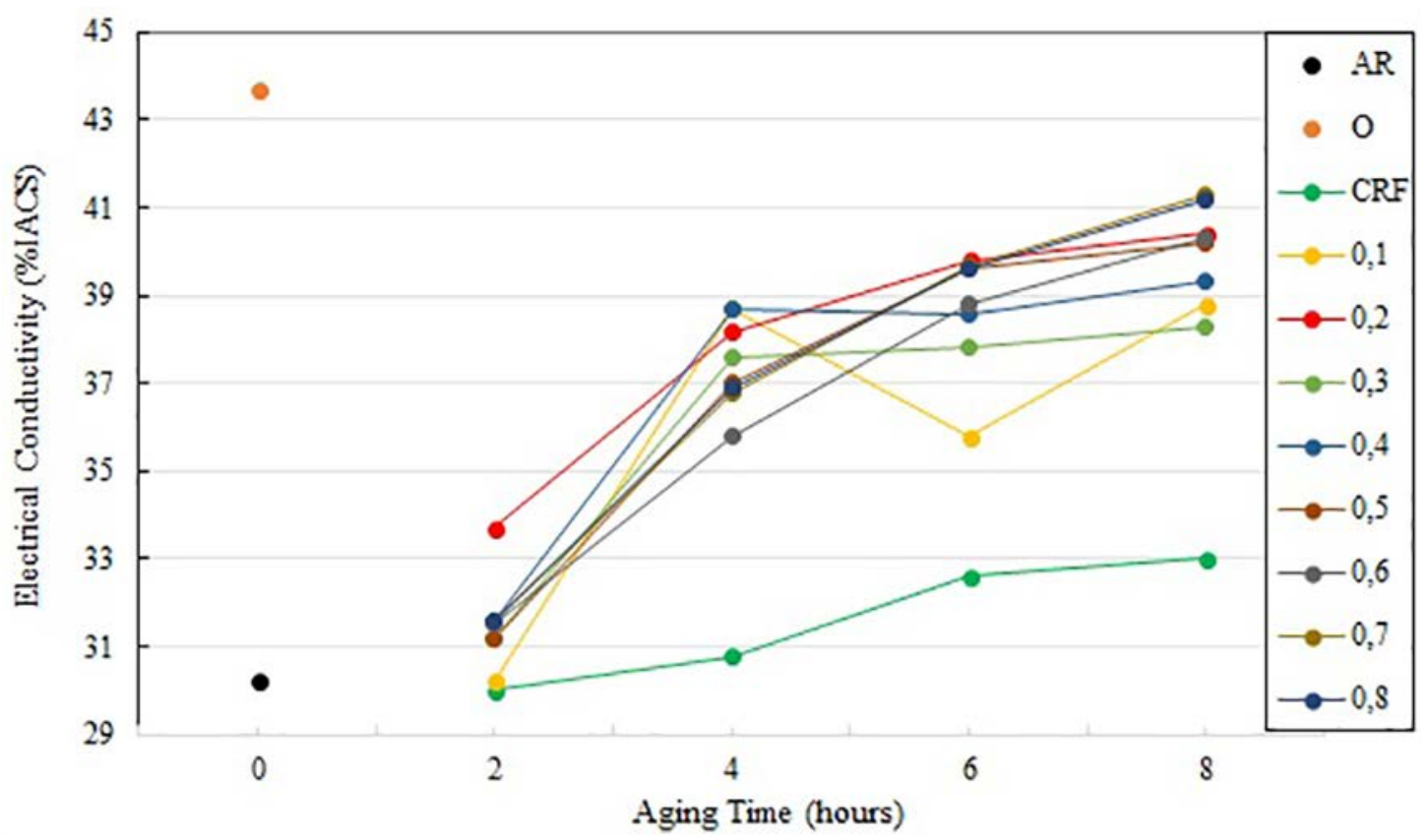

Figure 14. Electrical conductivity for aluminium alloy AA2024 in different conditions.

It can be observed in Figure 14 that the electrical conductivity increases with increasing aging time, for all conditions. Studied, suggesting that the first mechanism, described above, overlaps the second.

For cold worked samples, in addition to the phenomena mentioned above that affect the electrical conductivity, during aging also occurs recovery (reduction of punctual defects, rearrangement/elimination of dislocations) which contributes to the increase of electrical conductivity, as it reduces the obstacles present in the matrix, facilitating the movement of electrons.

\section{Conclusions}

For processing route proposed in this work, we found that for constant temperature precipitation / artificial aging $\left(190^{\circ} \mathrm{C}\right)$, long treatment times are necessary to obtain the maximum rupture strain values and Vickers hardness for samples not laminated. This behavior can be attributed to precipitation hardening, in which the 2 nd phase particles require longer times to nucleation and growth of precipitates. The contribution of this factor associated with hardening factor due to cold plastic deformation, contributed to further enhance the mechanical properties of AA2024 alloy. In this case, the maximum value of Vickers hardness was obtained at significantly shorter times, regardless of the degree of plastic deformation applied. It is noteworthy that, for understanding the behavior of the mechanical properties of the alloy, lower treatment times can indicate the maximum value obtained from properties, which can not be said with the minimum time used in this study (2 hours).
This study set a route of treatment to enable manufacture to alloys without structural damage and get even superior properties of required and / or reduce costs unnecessary treatments too lengthy.

\section{Acknowledgements}

The authors thank the Brazilian agencies CNPq, Capes, and FAPEMIG for the financial support.

\section{References}

1. Brown TJ, Walters AS, Idoine NE, Shaw RA, Wrighton CE, Bide T. World mineral production 2006-2010. $1^{\text {st }}$ ed. Nottingham: British Geological Survey; 2012.

2. Rosales BM, Iannuzzi M. Aluminium AA2024 T351 aeronautical alloy: Part 1. Microbial influenced corrosion analysis. Materials Science and Engineering: A. 2008;472(1-2):15-25.

3. Sha G, Marceau RKW, Gao X, Muddle BC, Ringer SP. Nanostructure of aluminium alloy 2024: Segregation, clustering and precipitation processes. Acta Materialia. 2011;59(4):1659-1670.

4. An LH, Cai Y, Liu W, Yuan SJ, Zhu SQ, Meng FC. Effect of predeformation on microstructure and mechanical properties of 2219 aluminum alloy sheet by thermomechanical treatment. Transactions of Nonferrous Metals Society of China. 2012;22(Suppl2):s370-s375.

5. Ghosh SK. Influence of Cold Deformation on the Aging Behaviour of Al-Cu-Si-Mg Alloy. Journal of Materials Science \&Technology. 2011;27(3):193-198.

6. Moy CKS, Weiss M, Xia J, Sha G, Ringer SP, Ranzi G. Influence of heat treatment on the microstructure, texture and formability of 2024 aluminium alloy. Materials Science and Engineering: A. 2012;552:48-60. 
7. Dursun T, Soutis C. Recent developments in advanced aircraft aluminium alloys. Materials \& Design (1980-2015). 2014;56:862-871.

8. ASM International Handbook Committee. ASM Handbook Volume 2: Properties and Selection: Nonferrous Alloys and Special-Purpose Materials. Materials Park: ASM International; 1990.

9. ASTM International. ASTM E384 - 17 - Standard Test Method for Microindentation Hardness of Materials. West Conshohocken: ASTM International; 2017.

10. ASTM International. ASTM E8 - 00b - Standard Test Methods for Tension Testing of Metallic Materials. West Conshohocken: ASTM International; 2001.

11. Radutoiu N, Alexis J, Lacroix L, Petit JA, Abrudeanu M, Rizea $\mathrm{V}$, et al. Effect of the Over-ageing Treatment on the Mechanical Properties of AA2024 Aluminum Alloy. Revista de Chimie (Bucharest). 2012;63(10):1042-1045.

12. Ning AL, Liu ZY, Zeng SM. Effect of large cold deformation on characteristics of age-strengthening of 2024 aluminum alloys. Transactions of Nonferrous Metals Society of China. 2006;16(5):1121-1128.

13. Song M, He YH, Xiao DH, Huang BY. Effect of thermomechanical treatment on the mechanical properties of an $\mathrm{Al}-\mathrm{Cu}-\mathrm{Mg}$ alloy. Materials \& Design. 2009;30(3):857-861.

14. Zhu Z, Starink MJ. Age hardening and softening in cold-rolled Al-Mg-Mn alloys with up to $0.4 \mathrm{wt} \% \mathrm{Cu}$. Materials Science and Engineering: A. 2008;489(1-2):138-149.

15. Bagaryatsky YA. Structural changes on aging Al-Cu-Mg alloys. Doklady Akademii nauk SSSR. 1952;87(3):397-401.
16. Elgallad EM, Shen P, Zhang Z, Chen GX. Effects of heat treatment on the microstructure and mechanical properties of AA2618 DC cast alloy. Materials \& Design. 2014;61:133140.

17. Naimi A, Yousfi H, Trari M. Influence of cold rolling degree and ageing treatments on the precipitation hardening of 2024 and 7075 alloys. Mechanics of Time-Dependent Materials. 2013;17(3):285-296.

18. Sjölander E, Seifeddine $\mathrm{S}$. The heat treatment of Al-Si-Cu-Mg casting alloys. Journal of Materials Processing Technology. 2010;210(10):1249-1259.

19. Liu Z, Chong PH, Butt AN, Skeldon P, Thompson GE. Corrosion mechanism of laser-melted AA 2014 and AA 2024 alloys. Applied Surface Science. 2005;247(1-4):294-299.

20. Schneider M, Yezerska O, Lohrengel MM. Anodic oxide formation on AA2024: electrochemical and microstructure investigation. Corrosion Engineering, Science and Technology. 2008;43(4):304-312.

21. Hughes AE, Glenn AM, Wilson N, Moffatt A, Morton AJ, Buchheit RG. A consistent description of intermetallic particle composition: An analysis of ten batches of AA2024-T3. Surface and Interface Analysis. 2013;45(10):1558-1563.

22. Wang SC, Starink MJ. Precipitates and intermetallic phases in precipitation hardening $\mathrm{Al}-\mathrm{Cu}-\mathrm{Mg}-(\mathrm{Li})$ based alloys. International Materials Reviews. 2005;50(4):193-215.

23. Abbasian A, Kashefi M, Ahmadzade-Biraki E. Quality control of precipitation hardened aluminium alloy parts via eddy-current nondestructive evaluation. Iranian Journal of Materials Science \& Engineering. 2015;12(3):83-87. 